\title{
Role of Red Meat and Resistant Starch in Promutagenic Adduct Formation, MGMT Repair, Thymic Lymphoma and Intestinal Tumourigenesis in Msh2-Deficient Mice
}

\author{
Jean M. Winter ${ }^{a}$ Ying $\mathrm{Hu}^{\mathrm{a}} \quad$ Graeme P. Young ${ }^{\mathrm{a}}$ \\ Maija R.J. Kohonen-Corish ${ }^{b, c}$ Richard K. Le Leu ${ }^{a}$ d \\ a Flinders Centre for Innovation in Cancer, Flinders University, Bedford Park, S.A., \\ ${ }^{b}$ Kinghorn Cancer Centre, Garvan Institute of Medical Research, and 'St Vincent's Medical \\ School, UNSW Australia, Sydney, N.S.W., and ' Food and Nutrition Flagship, Commonwealth \\ Scientific and Industrial Research Organisation, Adelaide, S.A., Australia
}

\section{Key Words}

Red meat $\cdot$ Resistant starch $\cdot \mathrm{O}^{6}$-methyl-2-deoxyguanosine $\cdot$ Mismatch repair .

Methylguanine methyltransferase

\begin{abstract}
Red meat may increase promutagenic lesions in the colon. Resistant starch (RS) can reduce these lesions and chemically induced colon tumours in rodents. Msh2 is a mismatch repair (MMR) protein, recognising unrepaired promutagenic adducts for removal. We determined if red meat and/or RS modulated DNA adducts or oncogenesis in Msh2-deficient mice. A total of $100 \mathrm{Msh}^{-/-}$and 60 wild-type mice consumed 1 of 4 diets for 6 months: control, RS, red meat and red meat + RS. Survival time, aberrant crypt foci (ACF), colon and small intestinal tumours, lymphoma, colonic $\mathrm{O}^{6}$-methyl-2-deoxyguanosine $\left(\mathrm{O}^{6} \mathrm{MeG}\right)$ adducts, methylguanine

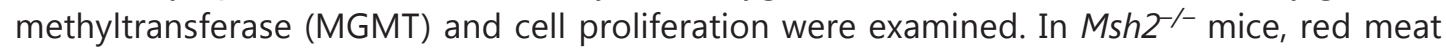
enhanced survival compared to control $(p<0.01)$ and lowered total tumour burden compared to RS ( $p<0.167)$. Msh2 $2^{-1}$ mice had more ACF than wild-type mice $(p<0.014)$, but no colon

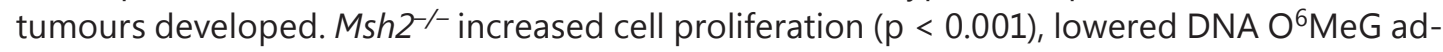
ducts ( $p<0.143)$ and enhanced MGMT protein levels $(p<0.001)$ compared to wild-type mice, with RS supplementation also protecting against DNA adducts $(p<0.01)$. No link between red meat-induced promutagenic adducts and risk for colorectal cancer was observed after 6 months' feeding. Colonic epithelial changes after red meat and RS consumption with MMR deficiency will differ from normal epithelial cells.

(C) 2015 S. Karger AG, Basel
\end{abstract}

This paper was presented at the 8th Congress of the International Society of Nutrigenetics/Nutrigenomics (ISNN), Gold Coast, Qld., Australia, May 2-3, 2014. 
Winter et al.: Role of Red Meat and RS in Promutagenic Adduct Formation, MGMT Repair, Thymic Lymphoma and Intestinal Tumourigenesis in Msh2-Deficient Mice

\section{Introduction}

Diet has long been known to play a pivotal role in determining the risk for colorectal cancer (CRC). Recent global statistics published by the WHO International Agency for Research on Cancer identifies CRC as the third most diagnosed cancer worldwide, with over 1.36 million cases in 2012 [1]. The report also identifies developed countries such as Australia and Europe with the highest incidence rates, while low-income countries in continents such as Africa having the lowest. Several decades ago, Burkitt [2] recognised that the component of a Western diet containing low dietary fibre and highly refined carbohydrates could be the most important factor attributed to high rates of CRC in developed countries. Not long thereafter, Armstrong and Doll [3] identified an association between red meat consumption and cancer, particularly CRC. Currently, the World Cancer Research Fund identifies red meat and processed red meats as a substantial risk factor for the development of CRC, whereas high dietary fibre, grains and starchy compounds are probably protective [4].

The mechanisms by which red meat might initiate or promote CRC are still being debated. Such processes include: oxidative stress and hyperproliferation by heme [5]; saturated fat promoting tumour formation via secondary bile acid production and lipid peroxidation [6]; protein fermentation by luminal microbiota generating toxic products [7]; carcinogen formation with high-temperature cooking of red meat [8], and lastly, endogenous and exogenous production of alkylating N-nitroso compounds (NOC) that induce alkyl adducts in the DNA [9]. Rodent models incorporating chemically derived alkylating agents can generate large amounts of DNA $0^{6}$-methyl-2-deoxyguanosine $\left(0^{6} \mathrm{MeG}\right)$ adducts in colonic epithelial cells and are directly linked with an increase in aberrant crypt foci (ACF) and colorectal tumours $[10,11]$. The first line of defence against these lesions involves the $0^{6}$-methylguanine DNA-methyltransferase (MGMT) repair protein sequestering the $0^{6} \mathrm{MeG}$ adduct in a suicide reaction. Without MGMT repair, the DNA polymerase complex recognises unrepaired $0^{6} \mathrm{MeG}$ adducts incorrectly, resulting in $\mathrm{GC} \rightarrow \mathrm{AT}$ transition mutations, after which other repair complexes including mismatch repair (MMR) are recruited [12]. A diet with high amounts of red meat in humans is demonstrated to generate significant NOC in faecal content, and this correlates with alkyl adduct formation within exfoliated rectal epithelial cells [13]. In rodents, short-term consumption of dietary red meat can increase colonic $0^{6} \mathrm{MeG}$ adducts compared to a non-meat protein source [9]. The production of known promutagenic alkyl adducts in the colon by red meat consumption may play a defining role in the oncogenesis of the colon and might act as a biomarker for red meat intake and the associated cancer risk.

Resistant starch (RS) is the component of starch delivered to the colon and fermented by the resident bacteria. It is thought that RS may protect against cancer through mechanisms associated with metabolic products of anaerobic bacterial fermentation in the colon [14]. Studies in rodents have shown associations between faecal short chain fatty acid (SCFA) production by RS and protection against hyperproliferation, preneoplastic markers and CRC [15-17]. In addition, rodents fed a high-protein diet display increased colonic DNA strand breaks, particularly with red meat consumption, but RS could protect against their formation [18-20]. More recently, RS has been identified as an inhibitor of red meat-induced promutagenic $0^{6} \mathrm{MeG}$ adducts in the mouse, an effect that correlated with faecal butyrate levels [9]. In human trials, RS has shown to reduce colonic proliferation in the colon of CRC patients [21] and healthy individuals consuming a diet with high amounts of red meat [22]. However, due to inadequate RS doses, the effects on epithelial kinetics and adenoma prevention in human trials are somewhat conflicting $[23,24]$. RS demonstrates potential for reducing the risk for CRC associated with a Western lifestyle, particularly when consuming a diet with high amounts of red meat. To date, the combination of red meat and RS has not been studied regarding CRC risk at later time points of the oncogenesis pathway, such as precancerous lesions and tumours. 
A majority of studies to date use the carcinogen azoxymethane (AOM), an alkylating agent that generates high levels of promutagenic adducts in the distal colon. Therefore, chemical carcinogenic exposure in rodent models of CRC is not an ideal representative of natural dietary carcinogenic exposures. An alternative model for studying dietary effects on CRC are genetically modified rodents that already exhibit an increased susceptibility to CRC. Knockout mice deficient in the Msh2 protein lack MMR capability and, as a consequence, generate more colonic tumours when exposed to AOM [25]. Although several genetic mouse models of cancer prevention with nutritional compounds have been used, the Msh2 knockout mouse has not been studied extensively [26]. In the human setting, loss of MMR underlies hereditary non-polyposis CRC (HNPCC), or Lynch syndrome, a common familial inherited form of CRC. HNPCC patients demonstrate increased rates of CRC compared to the normal population as well as earlier onset of disease [27]. In particular, HNPCC individuals with an Msh2 mutation have a higher age-specific cumulative risk for CRC of $48 \%$ by the age of 70 compared to the other common mutations MLH1 (41\%) and Msh6 (12\%) [28]. The Msh2 knockout mouse represents a relevant and potentially valuable model of study, particularly in relation to red meat-induced adducts and tumour outcome.

It is known that red meat is a risk factor for colorectal oncogenesis, and that RS has the capacity to reduce that risk. Consequently, we determined if feeding red meat to mice deficient in MMR capacity would increase $0^{6} \mathrm{MeG}$ DNA adducts, proliferation, preneoplastic lesions (ACF) and the risk for colonic neoplasia. We also determined if feeding RS could regulate these effects.

\section{Materials and Methods}

\section{Animals and Study Design}

Male and female $\mathrm{Msh}^{-/-}$mice initially bred on a 129/OLA background [29] but then backcrossed with C57Bl6J for multiple generations, and their wild-type litter mates, were imported from Australian BioResources (Moss Vale, N.S.W., Australia). A total of $100 \mathrm{Msh}^{-/-}$and 60 wild-type mice were used in the dietary study. All mice were placed into cages according to gender, with a maximum of 5 per cage. They were randomly divided into dietary groups and the feeding study was strictly under controlled conditions of $22 \pm 2{ }^{\circ} \mathrm{C}$ (SD), $80 \pm 10 \%$ humidity and 12-hour light/dark cycle. Mice were fed ad libitum and weighed once weekly throughout the entire study. The duration of dietary treatment was designed for 6 months, or until euthanasia attributed to illness. The original strain of Msh2 knockout mice demonstrate 1/3 survival at 19 weeks [29]. Msh2-deficient mice backcrossed with C57Bl6J for multiple generations demonstrate a better survival rate of $2 / 3$ at 19 weeks [30], i.e. double that of the original mouse strain. Therefore, due to the unexpected high rate of early lymphoma and small intestinal tumour development in several mice observed in the current study, an additional $36 \mathrm{Msh2^{-/ }}$ mice were included for analysis of cancer and precancerous end points. Research with animals was conducted according to the Australian code for the care and use of animals for scientific purposes. The Flinders University of South Australia Animal Welfare Committee approved all experimental procedures (ethics approval number 809/12).

Diets were based on the American Institute of Nutrition (AIN) diet AIN-76 with some modifications (table 1). A total of 4 dietary interventions were investigated: control, red meat, RS and red meat + RS. Red meat was cooked on a gas BBQ plate at the lowest temperature setting, dried overnight and ground to a powder before mixing in with the dry ingredients. Red meat was used at $25 \%$ dry weight, which is within the range of a typical Western diet [9]. Saturated fat content of the red meat final preparation was $10 \%$ and analysed by standard lipid extraction with a mixture of chloroform:methanol $(1: 1, \mathrm{v} / \mathrm{v})$ according to the method of Daugherty and Lento [31]. Lard was used in the non-red meat groups to control for saturated fat content of the red meat diet. Casein (Inpak Foods) was added at 20\% of the diet and used as a non-meat protein source in the control and RS diets. High-amylose maize starch (HAMS; Hi-maize 260) was used as the RS source (type RS2) at 10\% of the diet and was supplied by Ingredion ${ }^{\mathrm{TM}}$. The content of RS in HAMS is approximately 50\% [17]; therefore, a total of 5\% RS was in the final diet preparations. All 
Journal of
Nutrigenetics
Nutrigenomics

Table 1. Composition of experimental diets $(\mathrm{g} / 100 \mathrm{~g}$ of diet)

\begin{tabular}{l|l}
\hline J Nutrigenet Nutrigenomics 2014;7:299-313 \\
\hline DOI: $10.1159 / 000381675$ & $\begin{array}{l}\text { @ 2015 S. Karger AG, Basel } \\
\text { www.karger.com/jnn }\end{array}$ \\
\hline
\end{tabular}

Winter et al.: Role of Red Meat and RS in Promutagenic Adduct Formation, MGMT Repair, Thymic Lymphoma and Intestinal Tumourigenesis in Msh2-Deficient Mice

\begin{tabular}{|c|c|c|c|c|}
\hline & Control & RS & $\begin{array}{l}\text { Red } \\
\text { meat }\end{array}$ & $\begin{array}{l}\text { Red meat + } \\
\text { RS }\end{array}$ \\
\hline Casein & 20 & 20 & - & - \\
\hline Meat & - & - & 25 & 25 \\
\hline Corn starch & 41.72 & 31.64 & 39.25 & 29.17 \\
\hline Hi-Maize ${ }^{\mathrm{TM}}$ & - & 10 & - & 10 \\
\hline Sucrose & 10.95 & 10.95 & 10.95 & 10.95 \\
\hline Sunflower seed oil & 17.66 & 17.74 & 17.68 & 17.76 \\
\hline $\operatorname{Lard}^{\mathrm{a}}$ & 2.55 & 2.55 & - & - \\
\hline$\alpha$-Cellulose & 2 & 2 & 2 & 2 \\
\hline L-cysteine & 0.3 & 0.3 & 0.3 & 0.3 \\
\hline Choline & 0.17 & 0.17 & 0.17 & 0.17 \\
\hline Minerals ${ }^{\mathrm{b}}$ & 3.5 & 3.5 & 3.5 & 3.5 \\
\hline Vitamins $^{\mathrm{b}}$ & 1 & 1 & 1 & 1 \\
\hline DL-methionine & 0.15 & 0.15 & 0.15 & 0.15 \\
\hline Total & 100 & 100 & 100 & 100 \\
\hline
\end{tabular}

dry ingredients were mixed thoroughly before the wet ingredients were combined. Approximately 500-800 $\mathrm{ml}$ of distilled water was blended into the diet mixture before being compressed into pellets. Final pelleted food was stored in air-tight containers at $-20^{\circ} \mathrm{C}$ and replaced in the cage feeders every $1-2$ days.

\section{Specimen Collection, Storage and Tissue Preparation}

At the end of the 6-month feeding experiment, or when signs of deteriorating illness were evident, the mice were humanely euthanized by $\mathrm{CO}_{2}$ asphyxiation and cervical dislocation. The entire length of the colon was resected, faecal contents removed, and cut open longitudinally before being affixed to Hi-bond ${ }^{\mathrm{TM}}$ membrane paper. Colons were submerged in a $10 \%$ buffered formalin solution containing 3.6\% formaldehyde for $24 \mathrm{~h}$ and transferred to $70 \%$ ethanol for storage. The small intestine was examined and any suspected tumours were removed, placed into $10 \%$ buffered formalin solution and transferred to $70 \%$ ethanol at $24 \mathrm{~h}$. The diagnosis of lymphoma included but was not limited to: significant weight loss (10-15\%), deterioration of overall mouse health before death/euthanasia, rapid shallow breathing, enlarged thymus, spleen or liver, and/or lung tumour.

\section{Small Intestinal Tumour Histology}

Suspected small intestinal tumours were processed through gradient alcohols and xylene before being embedded in paraffin wax. A 5- $\mu$ m section was taken and rehydrated in gradient alcohols before staining with Harris haematoxylin and eosin for visualisation under light microscope. Tumours were classified as adenomas or adenocarcinomas. Adenomas were characterised by expansion of the mucosal layer, reduction in goblet cell number, moderate loss of mucosal architecture by glandular growth and dilated crypts. Adenocarcinomas were identified when there was severe distortion of cytological and glandular architecture, loss of cell polarity, prominent cellular atypia and invasion through the muscularis mucosae.

\section{Analysis of Colonic ACF}

Excess mucus and debris were washed from the colon with $0.9 \%$ solution of saline and gently wiped clean with a cotton tip before incubation in $0.4 \%$ solution of methylene blue diluted with $0.9 \%$ saline solution for approximately 1-2 min. Visualisation of ACF was performed under a dissecting microscope and identified as having crypts with large openings, unusual shape and stained darker than the normal surrounding crypts. ACF were classified as small ( $\leq 3$ aberrant crypts), large ( $\geq 4$ aberrant crypts) and total ACF. 


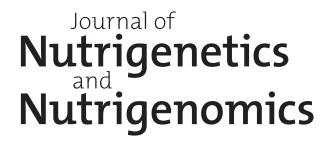

\begin{tabular}{l|l}
\hline J Nutrigenet Nutrigenomics 2014;7:299-313 \\
\hline DOI: $10.1159 / 000381675$ & $\begin{array}{l}\text { @ 2015 S. Karger AG, Basel } \\
\text { www.karger.com/jnn }\end{array}$ \\
\hline
\end{tabular}

Winter et al.: Role of Red Meat and RS in Promutagenic Adduct Formation, MGMT Repair, Thymic Lymphoma and Intestinal Tumourigenesis in Msh2-Deficient Mice

\section{Immunohistochemical Quantification of Proliferation, $O^{6} \mathrm{MeG}$ Adducts and MGMT Repair}

After ACF analysis, $0.5 \mathrm{~cm}$ of colorectal tissue was cut from the distal colon and from the proximal portion where the 'herringbone' pattern of the proximal colon meets the flatter, middle colon. Both small intestinal tumours and the colonic tissue segments were dehydrated through gradient alcohols and xylene before being embedded in paraffin wax. Distal and proximal sections of $4 \mu \mathrm{m}$ were used to quantify cell proliferation with an antibody against the nuclear proliferating antigen Ki-67 (AbCam SP6; cat. No. ab16667) and $0^{6} \mathrm{MeG}$ DNA adducts with the primary monoclonal antibody (clone EM 2-3; Squarix Biotechnology). Methods for immunohistochemical (IHC) protocols are described as per Winter et al. [9], with the exception of proximal colon tissue which used a primary $0^{6} \mathrm{MeG}$ antibody incubation temperature of $4^{\circ} \mathrm{C}$ instead of room temperature. The sum of intensity of $\mathrm{O}^{6} \mathrm{MeG}$ adduct staining for red meat and RS treatment was normalised relative to control diet levels. Slides were coded and a total of 20 intact colonic crypt columns were counted by a single observer who was blinded to dietary groups.

Quantification of MGMT protein was performed with a mouse monoclonal antibody (SPM287; cat. No. ab54306) diluted 4-fold with phosphate-buffered saline (PBS; pH 7.4) in combination with a mouse-onmouse polymer linking kit (Covance). Briefly, distal and proximal 4- $\mu \mathrm{m}$ sections were rehydrated with gradient alcohols, endogenous enzymes blocked with $3 \% \mathrm{H}_{2} \mathrm{O}_{2}$ in $50 \%$ ethanol for 15 min before antigen retrieval with $0.01 \mathrm{~mol} / \mathrm{l}$ citrate buffer ( $\mathrm{pH} 6.5$ ) for $1 \mathrm{~h}$ in a 2100 antigen retriever (PickCell Laboratories). Preblocking with normal serum block (Covance) for $15 \mathrm{~min}$ was performed before overnight incubation with the diluted MGMT antibody at $4^{\circ} \mathrm{C}$. Slides were washed in PBS $(3 \times 2 \mathrm{~min})$, followed by $30 \mathrm{~min}$ incubation with boost solution (Covance), washed again in PBS $(3 \times 2 \mathrm{~min}$ ) before $20 \mathrm{~min}$ incubation with mouse-onmouse polymer-HRP solution (Covance). Positive cells were visualised with DAB chromogen and substrate (Covance), and tissue sections were counterstained with Harris haematoxylin for observation under a light microscope. Proliferation was measured as positive Ki-67 cells per crypt column. $0^{6} \mathrm{MeG}$ and MGMT were calculated as the sum of pixel intensity (red to blue ratio) measured by computer image analysis (detailed in Winter et al. [9]). Slides were coded, and a total of 20 intact colonic crypt columns were counted by a single observer who was blinded to dietary groups.

\section{Statistical Analysis}

Cumulative survival of $M s h 2^{-/-}$mice is presented as Kaplan-Meier curves and generated using the original $100 \mathrm{Msh}^{-/-}$mice. Overall survival between all groups and the control versus red meat groups was analysed with the log-rank (Mantel-Cox) test. To avoid variation of adduct staining attributed to aging [32], IHC measurements of the colonic epithelia and final mouse bodyweights were analysed in 12 mice from each dietary group (both $\mathrm{Msh}^{-/-}$and wild type) that survived beyond 5 months. Data for $\mathrm{O}^{6} \mathrm{MeG}$ and MGMT were standardised to control the diet for each wild type and $M s h 2^{-/}$-mouse before comparison tests were carried out. Univariate analysis (three-way ANOVA) was used to identify effects and interactions of RS, red meat or genotype on final bodyweight, proliferation, $\mathrm{O}^{6} \mathrm{MeG}$ and MGMT. Due to the very small number of $\mathrm{Msh}^{-/-}$mice that developed ACF, an effect of RS or red meat was analysed using a generalised linear model (Wald $\chi^{2}$ test). Diet effects on small intestinal tumour incidence were analysed using a generalized linear model: ordinal $\operatorname{logistic}\left(\chi^{2}\right.$ test) and, for lymphoma incidence, crosstabs (Pearson's $\chi^{2}$ test). Overall tumour burden identified as the mean number of tumours per mouse was compared initially using one-way ANOVA with Bonferroni correction to adjust for multiple comparisons, followed by two-way ANOVA to identify the effects and interaction of red meat and RS on total tumour burden. Observed power for total tumour burden as the major endpoint was 0.245 , and for ACF the observed power was 0.111. All other observed power values for IHC variables measured were 0.816 for proliferation, 0.725 for $0^{6} \mathrm{MeG}$ adducts and 1.0 for MGMT. Data are represented as the mean \pm standard error (SE). Statistical significance was accepted at the $\mathrm{p}<0.05$ level.

\section{Results}

\section{Red Meat Improves Overall Survival and Demonstrates a Trend for Protection against} Tumour Burden in Msh2 ${ }^{-/-}$Mice

Overall food consumption was the same for each wild-type and Msh2-deficient mice (data not shown). Final bodyweights of both $M s h 2^{-/-}$and wild-type mice were not significantly affected by dietary treatment; however, $M s h 2^{-/-}$mice had significantly lower bodyweights 


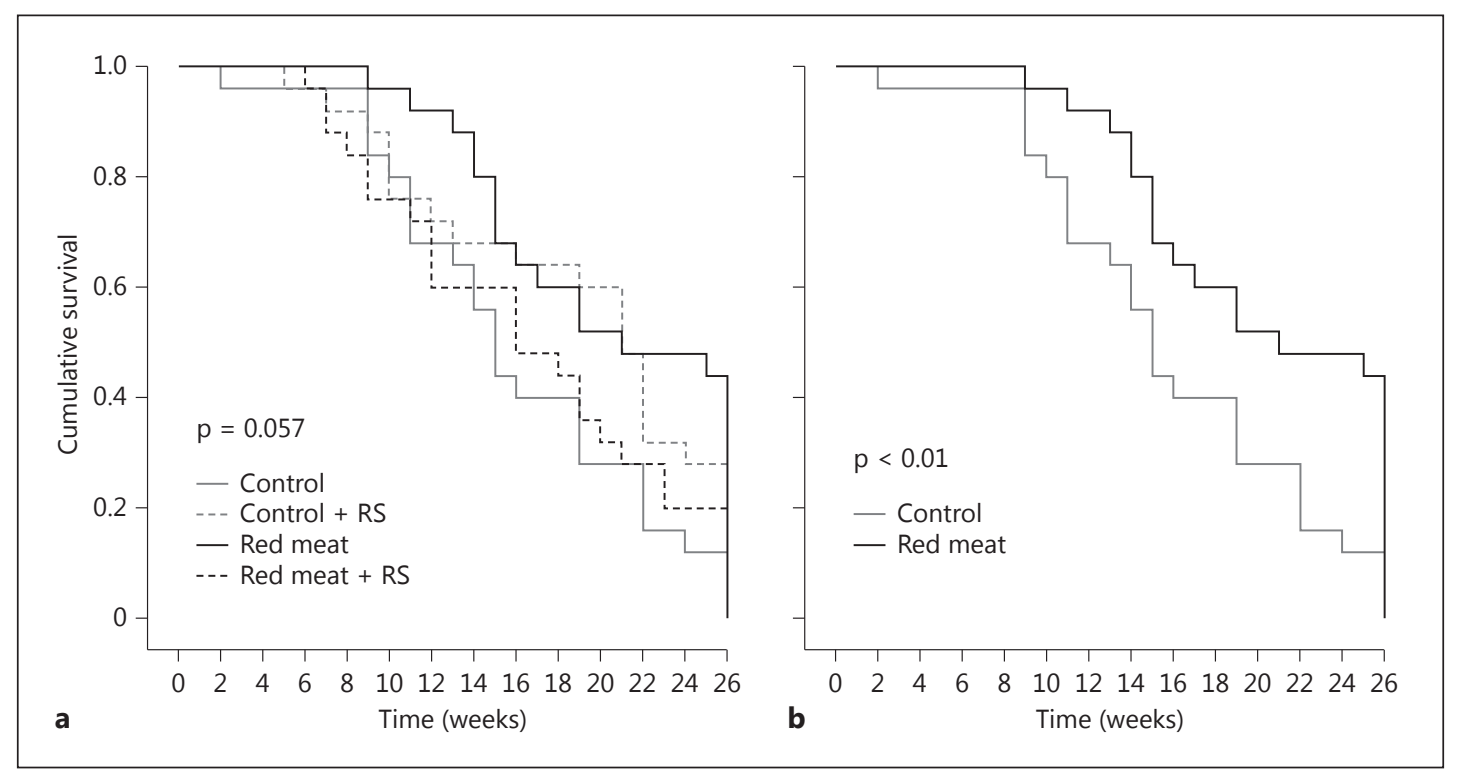

Fig. 1. Msh2 knockout survival. Cumulative survival of $M s h 2^{-/-}$mice over a 6-month dietary treatment (26 weeks) presented as Kaplan-Meyer curves showing comparisons of all dietary treatments (a) and control versus red meat diet (b).

Table 2. Incidence (\%) of colonic ACF, small intestinal (SI) tumours, lymphoma and mean total tumour burden in $\mathrm{Msh}^{-/-}$mice

\begin{tabular}{|c|c|c|c|c|c|c|}
\hline & \multicolumn{4}{|c|}{ Experimental diets } & \multicolumn{2}{|c|}{ Dietary effects, $p$ value ${ }^{2}$} \\
\hline & $\begin{array}{l}\text { control } \\
(n=35)\end{array}$ & $\begin{array}{l}\text { RS } \\
(n=31)\end{array}$ & $\begin{array}{l}\text { red meat } \\
(n=28)\end{array}$ & $\begin{array}{l}\text { red meat + RS } \\
(n=31)\end{array}$ & $\begin{array}{l}\text { RS } \\
\text { effect }\end{array}$ & $\begin{array}{l}\text { red meat } \\
\text { effect }\end{array}$ \\
\hline SI tumours & 20.6 & 30 & 10.7 & 22.6 & 0.194 & 0.412 \\
\hline Lymphoma & 38.2 & 33.3 & 28.6 & 35.5 & 0.625 & 0.520 \\
\hline Small ACF & 11.42 & 12.90 & 14.28 & 16.12 & 0.754 & 0.620 \\
\hline Large ACF & 0 & 3.225 & 7.142 & 3.225 & 0.987 & 0.286 \\
\hline Total ACF & 11.42 & 19.35 & 21.42 & 19.35 & 0.486 & 0.592 \\
\hline Total tumour burden ${ }^{1}$ & $0.69 \pm 0.13$ & $0.84 \pm 0.13$ & $0.43 \pm 0.11$ & $0.81 \pm 0.16$ & 0.249 & 0.343 \\
\hline
\end{tabular}

$(35.51 \pm 1.15)$ compared to wild-type mice $(40.61 \pm 1.12 ; \mathrm{p}<0.002)$. Comparison of overall survival for $\mathrm{Msh}^{-/-}$mice between all 4 diet groups did not reach statistical significance ( $\mathrm{p}=$ 0.057; fig. 1a). However, when comparing mice consuming control diet versus red meat diet, there was a statistically significant improvement in survival for those mice consuming the red meat diet ( $\mathrm{p}<0.01$; fig. 1b). Loss of Msh2 was associated with increased mean ACF per mouse from no ACF at all in the wild-type mice to $0.18 \pm 0.05(\mathrm{p}<0.05)$. There was no significant effect of any diet on small, large or total ACF. Overall, very few ACF were observed in any of the dietary groups (table 2). Msh2 ${ }^{-/-}$mice consuming a red meat diet had lower rates of both small intestinal tumours and lymphoma, although the difference was not significant (table 2). Analysis of the mean tumour burden per mouse (using one-way ANOVA) by combining small 


\section{Journal of \\ Nutrigenetics Nutrigenomics}

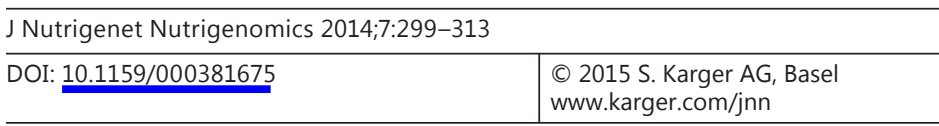

Winter et al.: Role of Red Meat and RS in Promutagenic Adduct Formation, MGMT Repair, Thymic Lymphoma and Intestinal Tumourigenesis in Msh2-Deficient Mice

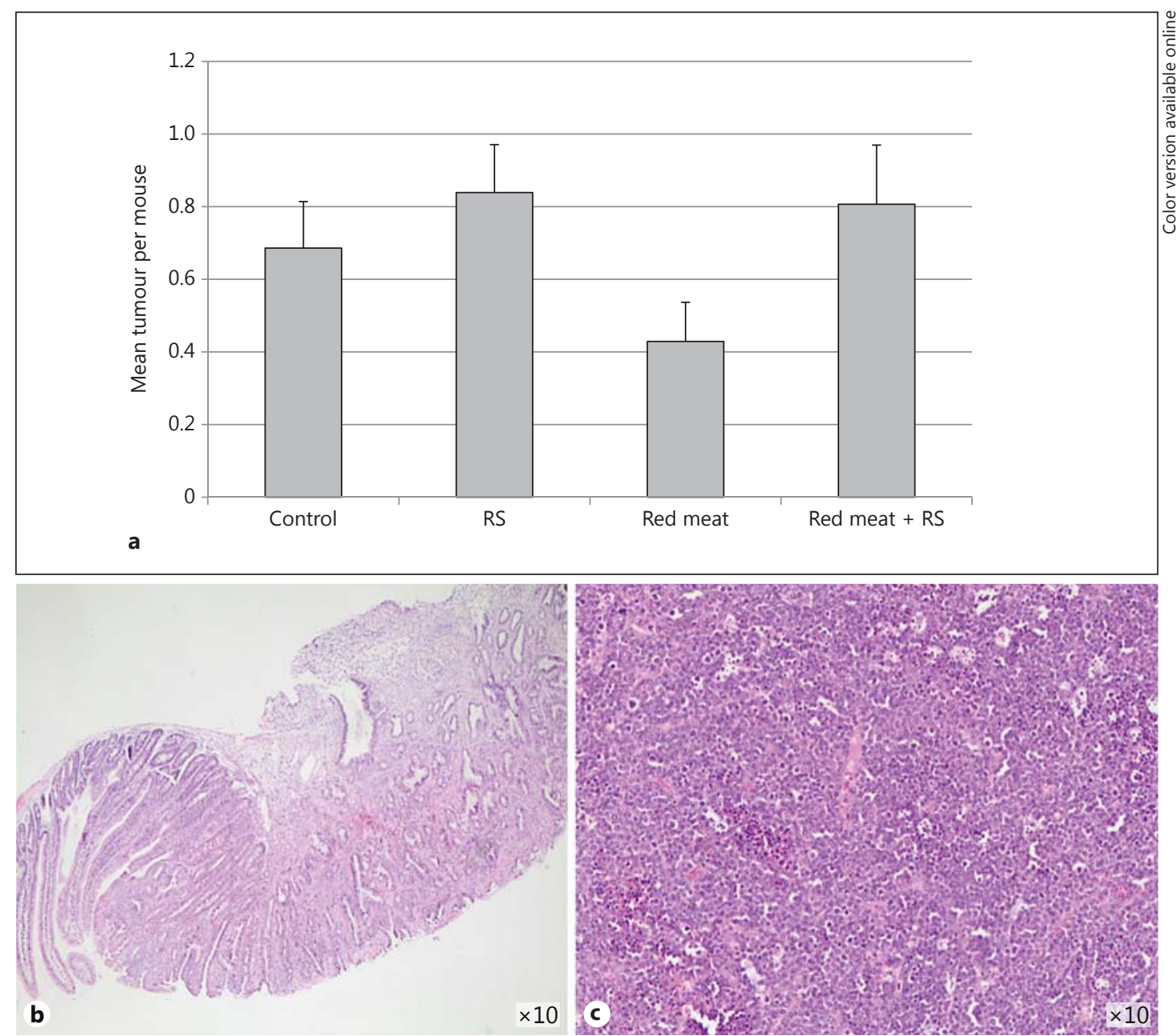

Fig. 2. a Total tumour burden of $M s h 2^{-/-}$mice combining small intestinal tumours and lymphoma. Analyses were carried out using one-way ANOVA with the Bonferroni correction to adjust for multiple comparisons. No significant differences were observed. Data are represented as mean \pm SE. Representative images of H\&E staining of normal-appearing epithelium and small intestinal adenocarcinoma (b) and a thymic lymphoma (c).

intestinal tumours and lymphoma (fig. 2) showed a trend for reduction in tumours with red meat compared to RS ( $\mathrm{p}<0.167)$. Analysis by two-way ANOVA showed there was no significant effect of red meat $(\mathrm{p}<0.343)$ or RS $(\mathrm{p}<0.249)$ on total tumour burden. No colorectal tumours (adenomas or invasive cancers) were observed in any mice.

\section{RS Protects against Msh2 ${ }^{-/-}$Hyperproliferation in the Distal Colon}

Proliferation rates in the distal colon for wild-type and $M s h 2^{-/-}$mice are shown in figure 3a. The level of positive Ki-67 cells per crypt was significantly higher in $M s h 2^{-/-}$mice compared to their wild-type litter mates $(\mathrm{p}<0.001)$. Hyperproliferation in $M s h 2^{-/-}$mice was supressed by addition of RS to the diet, although this did not reach significance ( $<<0.202$; fig. $3 b$ ). However, this effect of RS was not seen in the proximal colon (data not shown). In contrast, RS significantly increased proliferation in the proximal colon compared to diets without RS for wild-type mice $(\mathrm{p}<0.05)$, although this did not reach significance in $M s h 2^{-/-}$mice $(\mathrm{p}=$ 0.163 ; data not shown). 
Winter et al.: Role of Red Meat and RS in Promutagenic Adduct Formation, MGMT Repair, Thymic Lymphoma and Intestinal Tumourigenesis in Msh2-Deficient Mice

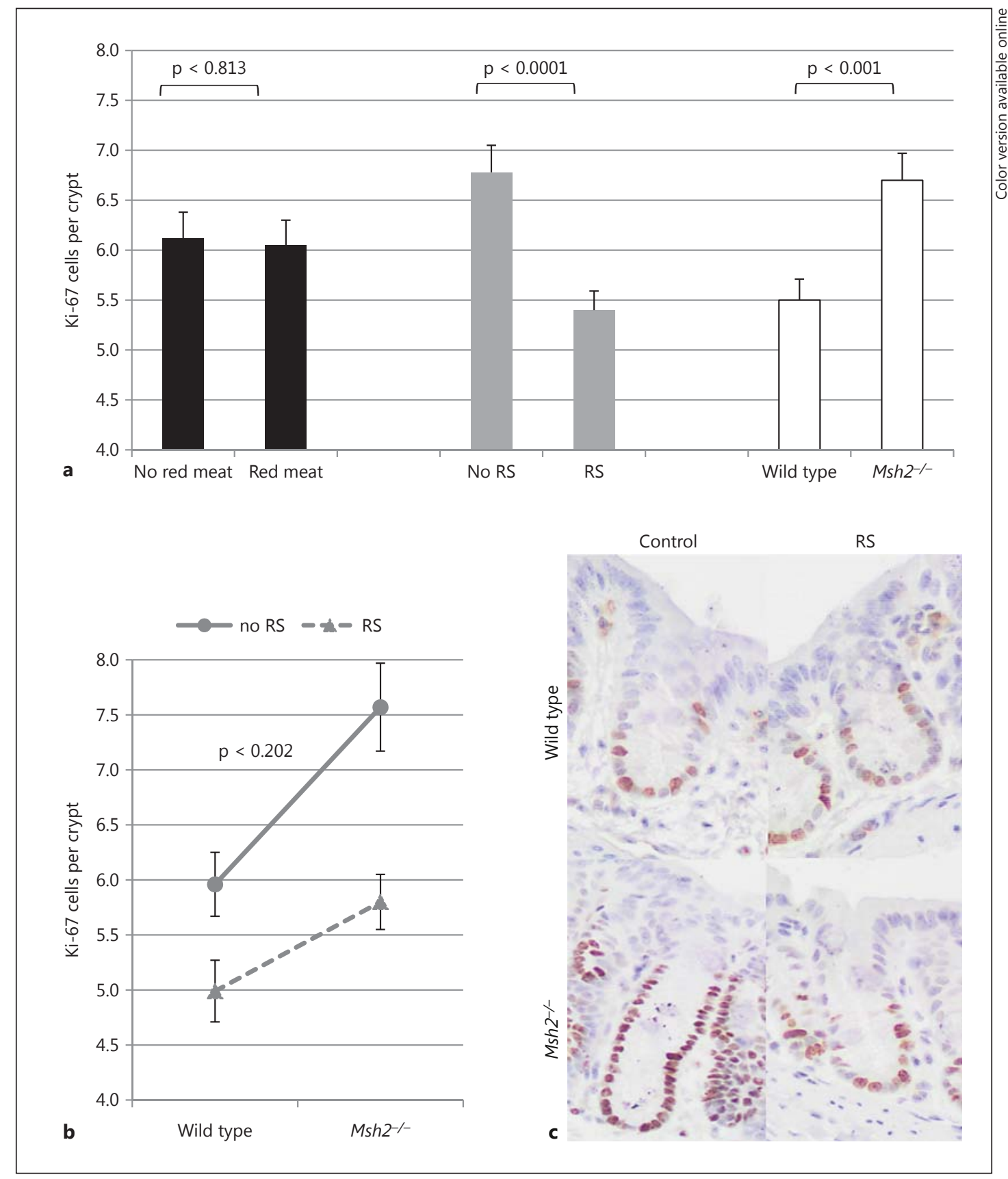

Fig. 3. a Effect of genotype, red meat and RS consumption on proliferation rates in the distal colon by threeway ANOVA. b Interaction of RS consumption and genotype by two-way ANOVA on distal colon proliferation. c Representative images showing the hyperproliferative state of distal colon in $M s h 2^{-/-}$mice and its reduction with RS supplementation. Data are represented as means \pm SE.

\section{$R S$ and Msh2 Deficiency Protects against $O^{6} \mathrm{MeG}$ DNA Adducts}

Results of $0^{6} \mathrm{MeG}$ DNA adducts normalised to control are presented in figure $4 \mathrm{a}$. Red meat did not significantly change $0^{6} \mathrm{MeG}$ adducts in the distal colon compared to mice consuming non-red meat diets $(\mathrm{p}<0.533)$. RS diets protected against $0^{6} \mathrm{MeG}$ adducts compared to non-RS diets $(\mathrm{p}<0.01)$. Loss of Msh2 did not enhance red meat-induced $0^{6} \mathrm{MeG}$ 


\section{Nutrigenomics}

Winter et al.: Role of Red Meat and RS in Promutagenic Adduct Formation, MGMT Repair, Thymic Lymphoma and Intestinal Tumourigenesis in Msh2-Deficient Mice

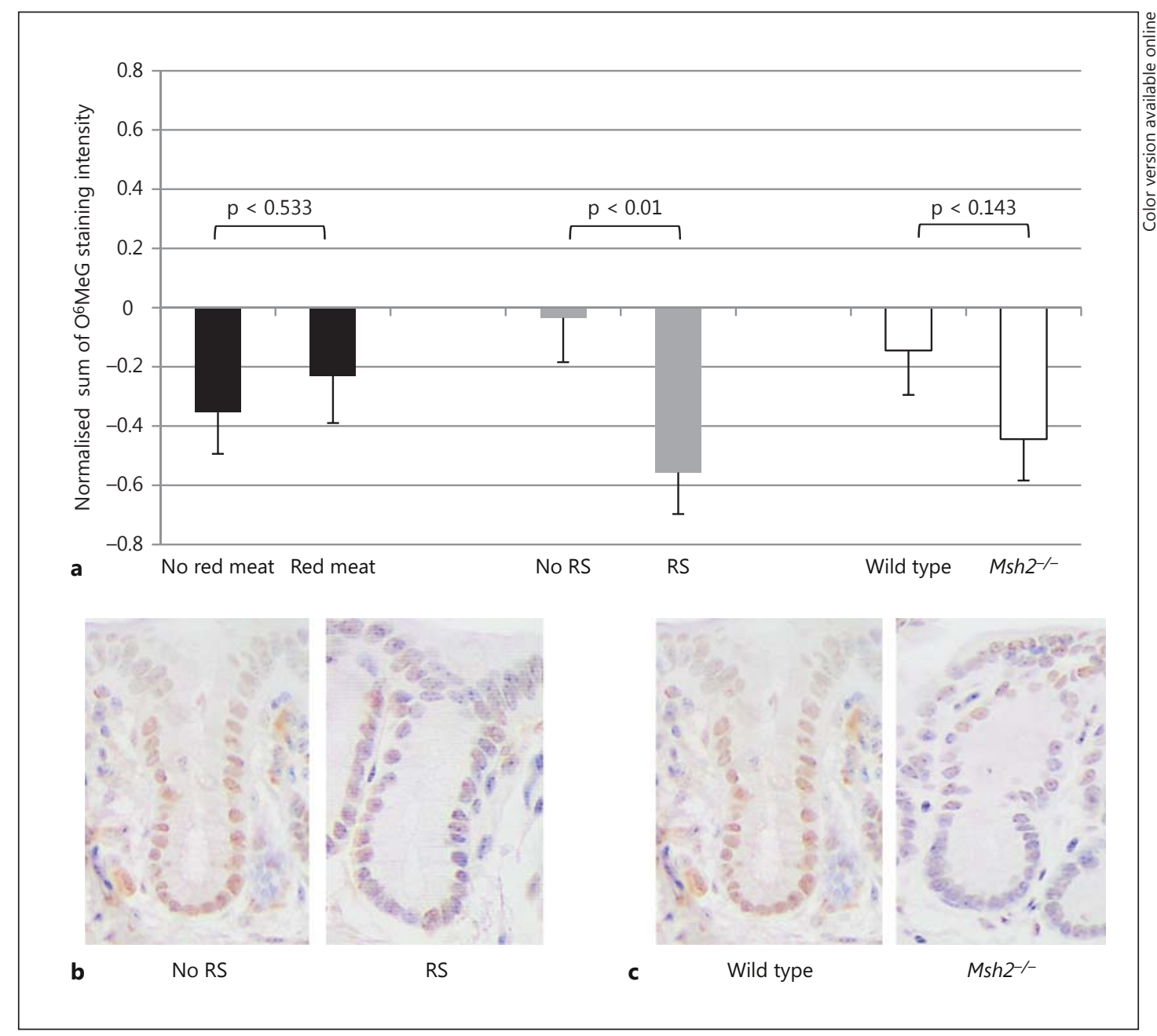

Fig. 4. a Main effects of red meat, RS and genotype on the sum of $0^{6} \mathrm{MeG} D N A$ adduct staining intensity normalised to control in distal colon cells. Representative images of $0^{6} \mathrm{MeG}$ DNA adduct IHC staining of the distal colon for RS versus non-RS diets (b) and wild-type versus $M s h 2^{-/-}$mice (c). Data are represented as mean \pm SE.

adducts (fig. 4a). In fact, $\mathrm{O}^{6} \mathrm{MeG}$ adducts demonstrated a trend of reduction in $\mathrm{Msh} 2^{-/-}$mice compared to wild-type mice ( $\mathrm{p}<0.143$ ). No significant changes in $0^{6} \mathrm{MeG}$ adduct accumulation were observed in the proximal colon (data not shown).

\section{MGMT Protein Expression Is Enhanced on an MMR-Deficient Background but Decreases} with RS Supplementation

To determine if changes in MGMT repair might be the mechanism by which $M s h 2^{-/-}$and RS supplementation display altered DNA adducts in mice, MGMT protein expression was measured in the distal colon. Msh2 ${ }^{-/-}$mice displayed significantly higher MGMT protein expression in the distal colon compared to wild-type mice $(\mathrm{p}<0.001)$. MGMT protein expression was significantly decreased in mice consuming RS diets compared to mice consuming diets without RS ( $\mathrm{p}<0.00001)$. Interaction tests between RS and genotype (fig. $5 \mathrm{~b}$ ) showed that MGMT activity was enhanced in $M s h 2^{-/-}$mice only consuming an RS diet, although this did not reach significance $(\mathrm{p}<0.118)$. 


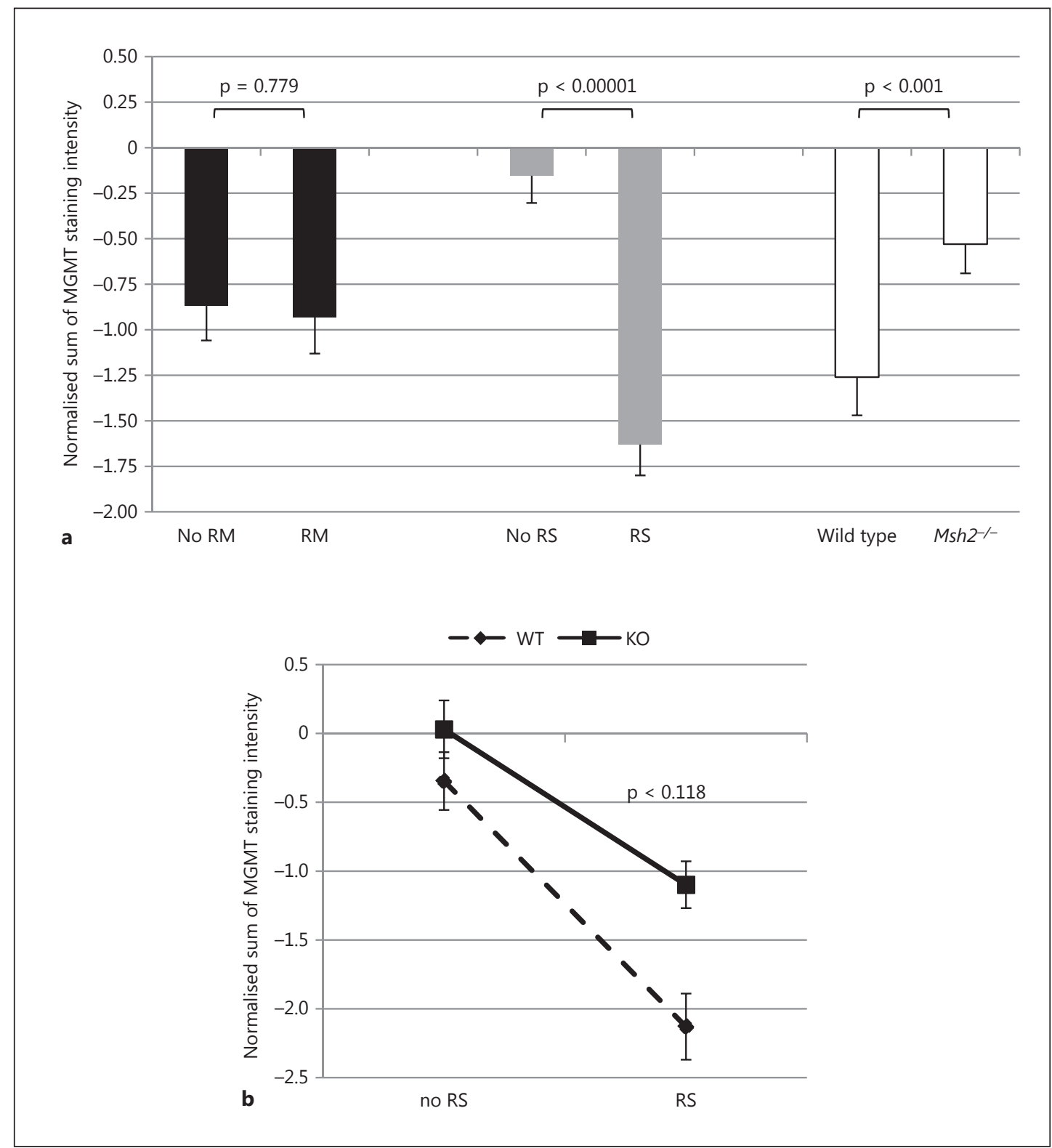

Fig. 5. Main effects of red meat, RS and genotype on the sum of MGMT DNA adduct staining intensity normalised to control in distal colon cells (a) and interaction of RS consumption and genotype by three-way ANOVA (b). Data are displayed as mean \pm SE. RM = Red meat; WT = wild type; $\mathrm{KO}=$ knockout.

\section{Discussion}

We have shown for the first time that the consumption of red meat demonstrates a trend for protection against lymphoma and small intestinal tumours in MMR-deficient mice, and that MMR deficiency has a protective effect on the formation of DNA promutagenic alkyl adducts in the distal colon. We have also shown for the first time that Msh2-deficient mice generate an adaptive response of MGMT protein expression. Moreover, we have confirmed previous data showing that RS consumption in normal mice can protect against the formation of these lesions in the distal colon. Loss of Msh2 capacity increased cell proliferation and spon- 
taneous ACF formation in the colon. Our results also show that a diet high in RS can impede $M s h 2^{-/-}$-associated hyperproliferation of the distal colon and return the epithelium to a more normal proliferative state. Yet, none of the observed changes with the dietary interventions had a significant effect on ACF or colon tumours within the 6-month duration of this experiment.

Contrary to our original hypothesis, red meat consumption in an Msh2-deficient mouse did not enhance unrepaired $0^{6} \mathrm{MeG}$ DNA adducts and was not a significant risk factor for ACF formation. However, DNA $0^{6} \mathrm{MeG}$ adduct accumulation was lower in Msh2-deficient mice compared to wild-type mice. What this means for CRC risk cannot be assessed since no animals developed CRC, certainly not within the 6-month duration of the experiment. Since MMR capacity is deficient in these mice, it seemed possible that Msh2-deficient mice might produce an adaptive response of MGMT repair to account for the loss of Msh2, thereby reducing unrepaired $0^{6} \mathrm{MeG}$ adduct load. Indeed, when we measured MGMT protein expression, we found a significant increase in MGMT expression in Msh2-deficient mice, indicating that an adaptive MGMT response is present in these mice when MMR is inefficient. Furthermore, there was a strong significant reduction in MGMT protein expression and reduction in $0^{6} \mathrm{MeG}$ adducts with RS supplementation, suggesting that RS primarily prevents these adducts from forming, thus negating the need for MGMT repair. This could be due to the bulking qualities of RS in the lumen reducing the contact time of potential carcinogens and mutagens with the epithelial cell layer [14]. Furthermore, RS consumption when on a highprotein diet switches fermentation from protein to carbohydrate, changing the metabolic profile $[9,32]$, and, therefore, could be reducing the alkylating capacity of the luminal contents by changing the microbiota diversity. Further studies measuring faecal metabolites such as NOC and analysing the microbiota profile might explain these findings. It is also important to note that the MGMT antibody used in the IHC analysis in the current study measures both active and inactive forms of MGMT. Therefore, MGMT activity levels may be different, even though changes in protein expression were identified. Due to inadequate tissue sampling in the mice, we were unable to measure MGMT activity, but future analysis of MGMT activity in Msh2-deficient mice is justified.

Although we detected changes in DNA adduct accumulation and enhanced MGMT repair with Msh2 deficiency, no effect on colonic proliferation or precancerous lesions (ACF) were identified, although a trend toward increasing large ACF was observed with red meat consumption ( $p$ 0.286). In humans, carriers of the MGMT Ile143Val polymorphism (which dampens MGMT activity) show a significant interaction of red meat and processed red meat intake ( $>56 \mathrm{~g} /$ day) and increased risk for CRC [33]. This suggests that accumulation of red meat-induced alkyl adducts due to ineffective MGMT activity might be important for the development of CRC in MMR-proficient individuals. However, carriers of the MMR gene defect do not display the same risk for CRC after the consumption of a diet with high amounts of red meat [34, 35]. Voskuil et al. [34] found an increased risk for CRC within a sporadic CRC population consuming red meat ranging from $<4$ times a week to $>7$ times a week $(p=0.08)$, but no such risk amongst the HNPCC population $(p=0.26)$. Meat consumption $>7$ times a week in this study demonstrated an OR of 4.1 (95\% CI 0.7-23) for sporadic CRC cases and only 0.4 (95\% CI 0.1-2.2) for HNPCC cases. These data, together with our MGMT and ACF results in $M s h 2^{-/-}$mice, suggest that the effect of red meat and MGMT repair in colonic epithelial cells with an MMR-deficient background might not be the same as in the general population. There appears to be an undetermined component of red meat, or apparent change in MGMT repair mechanism in MMR-deficient mice, that might protect against alkyl adduct formation as a result of MMR loss. Transition mutations in the $\mathrm{K}$-ras oncogene are known to be induced by alkylating agents [36] and could be explored in future studies to determine if these observed changes in adducts and MGMT effect K-ras mutation frequency in MMR-deficient mice 
consuming red meat and/or RS diets. The significance of the DNA $0^{6} \mathrm{MeG}$ adduct acting as a marker for exposure of red meat on a normal genetic background, and not necessarily as a biomarker of CRC risk, seems to be likely. However, the model used here may not have been entirely adequate to confirm this theory.

Unexpectedly, we observed a trend toward reduction in small intestinal tumours and lymphoma in MMR-deficient mice consuming a red meat diet, and a significantly enhanced survival rate in these mice. Msh2-/- mice develop intestinal tumours similar to HNPCC in older mice but spontaneous lymphomas occur at an earlier age (1/3 survival at 19.5 weeks) [29]. We hypothesised that red meat might act as an initiating 'carcinogen' (since we have shown that it increases adduct formation [9]), and that colonic neoplasms would develop (similar to chemical alkylation administration with AOM) as the MMR defect would make them more susceptible to the effects of red meat. Our results show that the $M s h 2^{-/-}$mouse is not a good model in determining CRC risk as a result of red meat consumption. It is possible that heterozygous Msh2 mice may be more informative. In fact, HNPCC patients are heterozygous carriers of an MMR gene defect and do not normally develop cancers in childhood. In contrast, children inheriting a homozygous MMR gene defect from families of affected HNPCC patients (MMR deficiency syndrome) have a distinct pathology of gastrointestinal cancers, hematologic malignancies and neurological tumours all occurring in early childhood [37]. In addition to MMR, Msh2 is also important for somatic intrachromosomal recombination [38], an important process in the protection against tumours via a properly functioning immune system. The role of red meat consumption and its apparent protective effect on malignancies associated with homozygous MMR deficiency is noteworthy. Whether red meat may be enhancing the immune system via other pathways within $M s h 2^{-/-}$mice, thereby reducing the risk for malignancies as a result of defective immune responses is unknown. More studies elucidating the effects of red meat on tumourigenesis and the immune system in an MMR-deficient background is needed to validate these findings.

Our findings support previous data $[9,39,40]$ emphasising how RS can reduce the proliferation and DNA alkyl adducts in the distal colon of wild-type rodents. We have also shown that functioning Msh2 protects against hyperproliferation and ACF formation in the colon, and that RS consumption protects against colonic hyperproliferation caused by the genetic defect of MMR. Previous research has shown that fermentation of RS in the rodent colon, both with and without red meat protein, generates significantly high levels of SCFAs in the colonic lumen, including butyrate $[9,19,20]$. Antineoplastic properties identified in vitro and in vivo highlight the butyrate's ability to increase the removal of highly damaged colon cells via apoptosis, as well as reducing cellular proliferation of the distal colon to allow for repair processes [41-43]. These effects of butyrate imply that it is responsible for reducing ACF and colon tumours in genetically normal rodents $[39,44]$ although no such reduction was evident in non-carcinogenic models of spontaneous CRC [32]. Reduction of hyperproliferation by RS was not seen in the proximal colon, and this could be due to the rapid formation of SCFAs once RS reaches the proximal colon from the caecum, with a steady decline in SCFAs further along the colon [45]. Butyrate is the primary energy source for colorectal cells and such a rise in SCFAs in this region of the colon might explain the increase in proliferation, and not necessarily a link to increased risk for cancer. Our ACF findings in $M s h 2^{-/-}$mice support data from the CAPP2 trial of HNPCC patients where RS consumption did not reduce CRC risk, although doses of RS in that study were arguably low at approximately $15 \mathrm{~g}$ of RS (in the $30 \mathrm{~g} /$ day of HAMS administered) [24, 46]. Maintaining colonic proliferation via RS fermentation may not reduce ACF formation induced by loss of MMR. In the current study, $M s h 2^{-/-}$mice did not live long enough for a substantial amount of ACF to form and longer intervention times may be required. RS may protect against CRC in chemical carcinogenic rodent models, but its chemoprotective capacity against cancer generated by a Western diet remains questionable. 
There were a few limitations in this study that affected the potential to produce definitive results. Firstly, the power of the study was not adequate to identify changes in tumour burden and ACF formation. This was likely due to very small numbers of ACF forming in the colon of Msh2-deficient mice, and a low number of remaining mice at the conclusion of the study due to extracolonic tumours forming. Secondly, the length of the study was inadequate to allow sufficient ACF and colon tumours to form; therefore, longer dietary intervention times would be needed in the future using a larger sample of $\mathrm{Msh}^{-/-}$mice. Lastly, using mice was an essential component of this study (due to the nature of the genetic knockout utilised); however, as a consequence tissue sampling was extremely limited. Therefore, important analyses were not feasible but may have proved more informative and supported our current findings.

Contrary to our hypotheses, this study has revealed an unexpected protective effect of MMR deficiency on colon $0^{6} \mathrm{MeG}$ adduct formation, likely as a consequence of an enhanced MGMT response in those mice. This study also reveals a trend of reduction in lymphoma and small intestinal cancer and an enhanced survival rate in $M s h 2^{-/-}$mice consuming red meat. However, we did not show a link between colonic promutagenic adducts and red meat consumption, or any associated risk for CRC. Although RS supressed hyperproliferation of the distal colon as a result of MMR deficiency, we did not identify any link between lowered proliferation rates and ACF formation. Consequently, the CRC risk associated with changes in colonic proliferation by RS fermentation in the context of MMR remains questionable. Variations in epithelial markers after red meat and RS consumption on a normal genetic background do not always behave in a similar fashion with MMR-deficient capacity. These findings highlight the potential implications for dietary guidelines given to individuals at high risk of developing CRC, particularly those with an inherited genetic defect in MMR.

\section{Acknowledgements}

The study was supported by the National Health and Medical Research Council of Australia (grant ID 535079 and 1020406). M.R.J.K.-C. was supported by Cancer Institute NSW Fellowship 10CDF232.

\section{Disclosure Statement}

The authors declare that they have no conflicts of interest.

\section{References}

1 Forman D, Bray F, Brewster DH, Gombe Mbalawa C, Kohler B, Piñeros M, et al (eds): Cancer Incidence in Five Continents. Lyon, International Agency for Research on Cancer, 2013, vol X. http://ci5.iarc.fr (accessed July 4, 2014).

2 Burkitt DP: Epidemiology of cancer of the colon and rectum. Cancer 1971;28:3-13.

-3 Armstrong B, Doll R: Environmental factors and cancer incidence and mortality in different countries, with special reference to dietary practices. Int J Cancer 1975; 15:617-631.

4 World Cancer Research Fund/American Institute for Cancer Research: Food, Nutrition, Physical Activity, and the Prevention of Cancer: A Global Perspective. Washington, American Institute for Cancer Research, 2007.

5 Santarelli RL, Vendeuvre JL, Naud N, Tache S, Gueraud F, Viau M, et al: Meat processing and colon carcinogenesis: cooked, nitrite-treated, and oxidized high-heme cured meat promotes mucin-depleted foci in rats. Cancer Prev Res (Phila) 2010;3:852-864.

6 Reddy BS: Dietary fat and colon cancer: animal model studies. Lipids 1992;27:807-813.

7 Le Leu RK, Young GP: Fermentation of starch and protein in the colon: implications for genomic instability. Cancer Biol Ther 2007;6:259-260.

-8 Zheng W, Lee SA: Well-done meat intake, heterocyclic amine exposure, and cancer risk. Nutr Cancer 2009;61: 437-446. 


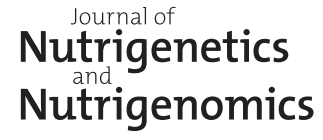

\begin{tabular}{l|l}
\hline J Nutrigenet Nutrigenomics 2014;7:299-313 \\
\hline DOI: $10.1159 / 000381675$ & $\begin{array}{l}\text { C 2015 S. Karger AG, Basel } \\
\text { www.karger.com/jnn }\end{array}$ \\
\hline
\end{tabular}

Winter et al.: Role of Red Meat and RS in Promutagenic Adduct Formation, MGMT

Repair, Thymic Lymphoma and Intestinal Tumourigenesis in Msh2-Deficient Mice

$\$ 9$ Winter J, Nyskohus L, Young GP, Hu Y, Conlon MA, Bird AR, et al: Inhibition by resistant starch of red meatinduced promutagenic adducts in mouse colon. Cancer Prev Res (Phila) 2011;4:1920-1928.

10 Jackson PE, O'Connor PJ, Cooper DP, Margison GP, Povey AC: Associations between tissue-specific DNA alkylation, DNA repair and cell proliferation in the colon and colon tumour yield in mice treated with 1,2-dimethylhydrazine. Carcinogenesis 2003;24:527-533.

$\checkmark 11$ Povey AC, Badawi AF, Cooper DP, Hall CN, Harrison KL, Jackson PE, et al: DNA alkylation and repair in the large bowel: animal and human studies. J Nutr 2002;132:3518S-3521S.

12 Margison GP, Santibanez Koref MF, Povey AC: Mechanisms of carcinogenicity/chemotherapy by 06-methylguanine. Mutagenesis 2002;17:483-487.

13 Lewin MH, Bailey N, Bandaletova T, Bowman R, Cross AJ, Pollock J, et al: Red meat enhances the colonic formation of the DNA adduct 06-carboxymethyl guanine: implications for colorectal cancer risk. Cancer Res 2006;66:1859-1865.

14 Young GP, Le Leu RK: Resistant starch and colorectal neoplasia. J AOAC Int 2004;87:775-786.

15 Bauer-Marinovic M, Florian S, Muller-Schmehl K, Glatt H, Jacobasch G: Dietary resistant starch type 3 prevents tumor induction by 1,2-dimethylhydrazine and alters proliferation, apoptosis and dedifferentiation in rat colon. Carcinogenesis 2006;27:1849-1859.

$\checkmark 16$ Le Leu RK, Brown IL, Hu Y, Morita T, Esterman A, Young GP: Effect of dietary resistant starch and protein on colonic fermentation and intestinal tumourigenesis in rats. Carcinogenesis 2007;28:240-245.

$\checkmark 17$ Le Leu RK, Hu Y, Brown IL, Young GP: Effect of high amylose maize starches on colonic fermentation and apoptotic response to DNA-damage in the colon of rats. Nutr Metab (Lond) 2009;6:11.

18 Toden S, Bird AR, Topping DL, Conlon MA: Resistant starch attenuates colonic DNA damage induced by a high protein diet in rats. Asia Pac J Clin Nutr 2003;12(suppl):S13.

19 Toden S, Bird AR, Topping DL, Conlon MA: High red meat diets induce greater numbers of colonic DNA doublestrand breaks than white meat in rats: attenuation by high-amylose maize starch. Carcinogenesis 2007;28: 2355-2362.

20 Toden S, Bird AR, Topping DL, Conlon MA: Resistant starch prevents colonic DNA damage induced by high dietary cooked red meat or casein in rats. Cancer Biol Ther 2006;5:267-272.

-21 Dronamraju SS, Coxhead JM, Kelly SB, Burn J, Mathers JC: Cell kinetics and gene expression changes in colorectal cancer patients given resistant starch: a randomised controlled trial. Gut 2009;58:413-420.

-22 Humphreys KJ, Conlon MA, Young GP, Topping DL, Hu Y, Winter JM, et al: Dietary manipulation of oncogenic microRNA expression in human rectal mucosa: a randomized trial. Cancer Prev Res (Phila) 2014;7:786-795.

23 van Gorkom BA, Karrenbeld A, van der Sluis T, Zwart N, van der Meer R, de Vries EG, et al: Calcium or resistant starch does not affect colonic epithelial cell proliferation throughout the colon in adenoma patients: a randomized controlled trial. Nutr Cancer 2002;43:31-38.

24 Burn J, Bishop DT, Mecklin JP, Macrae F, Moslein G, Olschwang S, et al: Effect of aspirin or resistant starch on colorectal neoplasia in the Lynch syndrome. N Engl J Med 2008;359:2567-2578.

25 Mladenova D, Daniel JJ, Dahlstrom JE, Bean E, Gupta R, Pickford R, et al: The NSAID sulindac is chemopreventive in the mouse distal colon but carcinogenic in the proximal colon. Gut 2011;60:350-360.

26 Tammariello AE, Milner JA: Mouse models for unraveling the importance of diet in colon cancer prevention. J Nutr Biochem 2010;21:77-88.

27 Lynch HT, Lanspa S, Smyrk T, Boman B, Watson P, Lynch J: Hereditary nonpolyposis colorectal cancer (Lynch syndromes I and II). Genetics, pathology, natural history, and cancer control, Part I. Cancer Genet Cytogenet 1991;53:143-160.

28 Bonadona V, Bonaiti B, Olschwang S, Grandjouan S, Huiart L, Longy M, et al: Cancer risks associated with germline mutations in MLH1, MSH2, and MSH6 genes in Lynch syndrome. JAMA 2011;305:2304-2310.

29 de Wind N, Dekker M, van Rossum A, van der Valk M, te Riele H: Mouse models for hereditary nonpolyposis colorectal cancer. Cancer Res 1998;58:248-255.

-30 Reitmair AH, Redston M, Cai JC, Chuang TC, Bjerknes M, Cheng H, et al: Spontaneous intestinal carcinomas and skin neoplasms in Msh2-deficient mice. Cancer Res 1996;56:3842-3849.

-31 Daugherty CE, Lento HG: Chloroform-methanol extraction method for determination of fat in foods: collaborative study. J Assoc Off Anal Chem 1983;66:927-932.

32 Winter J, Young GP, Hu Y, Gratz SW, Conlon MA, Le Leu RK: Accumulation of promutagenic DNA adducts in the mouse distal colon after consumption of heme does not induce colonic neoplasms in the western diet model of spontaneous colorectal cancer. Mol Nutr Food Res 2014;58:550-558.

-33 Loh YH, Mitrou PN, Bowman R, Wood A, Jeffery H, Luben RN, et al: MGMT Ile143Val polymorphism, dietary factors and the risk of breast, colorectal and prostate cancer in the European Prospective Investigation into Cancer and Nutrition (EPIC)-Norfolk study. DNA Repair (Amst) 2010;9:421-428.

-34 Voskuil DW, Kampman E, Grubben MJ, et al: Meat consumption and meat preparation in relation to colorectal adenomas among sporadic and HNPCC family patients in The Netherlands. Eur J Cancer 2002;38:2300-2308.

-35 Botma A, Vasen HF, van Duijnhoven FJ, Kleibeuker JH, Nagengast FM, Kampman E: Dietary patterns and colorectal adenomas in Lynch syndrome: the GEOLynch cohort study. Cancer 2013;119:512-521.

-36 McKinzie PB, Parsons BL: Accumulation of K-Ras codon 12 mutations in the F344 rat distal colon following azoxymethane exposure. Environ Mol Mutagen 2011;52:409-418.

-37 Bandipalliam P: Syndrome of early onset colon cancers, hematologic malignancies \& features of neurofibromatosis in HNPCC families with homozygous mismatch repair gene mutations. Fam Cancer 2005;4:323-333. 
-38 Hooker AM, Morley AA, Tilley WD, Sykes PJ: Cancer-associated genes can affect somatic intrachromosomal recombination early in carcinogenesis. Mutat Res 2004;550:1-10.

-39 Le Leu RK, Brown IL, Hu Y, Esterman A, Young GP: Suppression of azoxymethane-induced colon cancer development in rats by dietary resistant starch. Cancer Biol Ther 2007;6:1621-1626.

-40 Le Leu RK, Hu Y, Brown IL, Woodman RJ, Young GP: Synbiotic intervention of Bifidobacterium lactis and resistant starch protects against colorectal cancer development in rats. Carcinogenesis 2010;31:246-251.

-41 Hague A, Elder DJ, Hicks DJ, Paraskeva C: Apoptosis in colorectal tumour cells: induction by the short chain fatty acids butyrate, propionate and acetate and by the bile salt deoxycholate. Int J Cancer 1995;60:400-406.

-42 Le Leu RK, Brown IL, Hu Y, Young GP: Effect of resistant starch on genotoxin-induced apoptosis, colonic epithelium, and lumenal contents in rats. Carcinogenesis 2003;24:1347-1352.

43 Emenaker NJ, Calaf GM, Cox D, Basson MD, Qureshi N: Short-chain fatty acids inhibit invasive human colon cancer by modulating uPA, TIMP-1, TIMP-2, mutant p53, Bcl-2, Bax, p21 and PCNA protein expression in an in vitro cell culture model. J Nutr 2001;131:3041S-3046S.

44 Perrin P, Pierre F, Patry Y, Champ M, Berreur M, Pradal G, et al: Only fibres promoting a stable butyrate producing colonic ecosystem decrease the rate of aberrant crypt foci in rats. Gut 2001;48:53-61.

45 Topping DL, Clifton PM: Short-chain fatty acids and human colonic function: roles of resistant starch and nonstarch polysaccharides. Physiol Rev 2001;81:1031-1064.

46 Mathers JC, Movahedi M, Macrae F, Mecklin JP, Moeslein G, Olschwang S, et al: Long-term effect of resistant starch on cancer risk in carriers of hereditary colorectal cancer: an analysis from the CAPP2 randomised controlled trial. Lancet Oncol 2012;13:1242-1249. 